\title{
Repair of massive stent-induced tracheoesophageal fistula
}

Yong Han, MD, Kun Liu, MD, Xiaofei Li, MD, Xiaoping Wang, MD, Yongan Zhou, MD, Zhongping Gu, MD, Qunfeng Ma, MD, Tao Jiang, MD, Lijun Huang, MD, Tao Zhang, MD, and Qingshu Cheng, MD

Objective: The purpose of this report was to discuss a new surgical procedure in treating esophageal stent related large tracheoesophageal fistula without tracheal resection.

Methods: Clinical records of 5 patients with esophageal stent-related large tracheoesophageal fistulas treated in this hospital between 1997 and 2006 were reviewed.

Result: All patients had insertion of a covered self-expanding esophageal stent, 1 for benign esophageal stricture and 4 for esophageal perforation resulting from various causes. A double patch technique, in which the esophageal wall was used as a protective patch repairing the defect on the trachea, was performed with an esophagectomy and gastric replacement. No significant complications occurred in the perioperative period. All patients recovered uneventfully.

Conclusions: Use of the adjacent esophageal wall as a patch to close a defect on the trachea is a safe procedure with a favorable outcome. It should therefore be recommended as a reliable surgical procedure in treating massive stent-induced tracheoesophageal fistulas and other complicated tracheoesophageal fistulas that tracheal resection could not safely address. However, the esophagus was damaged to a certain degree.

Acquired tracheoesophageal fistula (TEF) usually results from erosion of the adjacent walls of the trachea and esophagus due to a variety of causes. Besides trauma and malignancy, cuff-related tracheal injury has become the most common etiology of these fistulas. ${ }^{1}$ However, several patients with TEF caused by esophageal stent-related injury were treated in our hospital. The esophageal stents were usually placed in the thoracic segments of the inflamed esophagus, and the fistulas were always too large for primary repair. Because of the large defect, persistent infection, and friability of the tissues, outcome and quality of life would be poor after tracheal resection. In our practice, 5 esophageal stentrelated TEF patients were treated without tracheal resection by a new surgical procedure in which the esophageal wall was applied as a protective patch on the fistula when the esophagus was damaged to a certain degree at the same time, and the results were satisfactory.

\section{CLINICAL DATA}

Our group comprised 4 male patients and 1 female patient. The youngest was 11 years old and the eldest 55 years with an average of 34.4 years. The main causative factor for TEF in every one of them was the placement of self-expanding esophageal stents. These were used in 4 cases for esophageal perforation resulting from various causes and in 1 case for

\footnotetext{
From the Department of Thoracic Surgery, Tangdu Hospital of The Fourth Military Medical University, Xi'an, Shaanxi, China.

Received for publication Feb 2, 2008; revisions received June 2, 2008; accepted for publication July 5, 2008.

Address for reprints: Qingshu Cheng, MD, Department of Thoracic Surgery Tangdu Hospital, The Fourth Military Medical University, Xi'an 710038 China (E-mail: chechest@fmmu.edu.cn).

J Thorac Cardiovasc Surg 2009;137:813-7

$0022-5223 / \$ 36.00$

Copyright (c) 2009 by The American Association for Thoracic Surgery

doi:10.1016/j.jtcvs.2008.07.050
}

esophageal stricture resulting from chemical burn in other hospitals. All of them had cough on swallowing, dysphagia, and dyspnea 2 months to 2 years after placement of the stents. The TEFs were located on the middle segment of the esophagus in 4 of the 5 patients and on the lower segment in the other patient. The length of defects on the membranous portion of the trachea ranged from 1 to $3 \mathrm{~cm}$.

\section{RESULT}

A double patch technique, in which the esophageal wall was used as a protective patch repairing the defect on the trachea, was applied to each of them despite the complexity and extent of the TEF. No significant complications occurred in the perioperative period. All the patients recovered uneventfully. They were followed up for 14 months to 9 years. All of them tolerated oral feeding normally with a good quality of life, and none of them showed any symptom or sign of recurrence of the TEF (Table 1).

\section{DOUBLE PATCH TEF REPAIR}

The double patch repair primarily creates a protective base over the massive defect on the membranous wall of the trachea to provide a solution for TEF when tracheal repair and resection cannot be undertaken safely and easily for various reasons: a long defect on the trachea, inflammation around the defect, technical difficulty in separating the esophagus from the trachea safely, difficulty in airway management, anesthesia, and other reasons. Furthermore, esophageal function was damaged to a certain degree or the defect was massive in the esophagus as well. We used the patient's own viable esophageal tissue to repair the TEF rather than applying tracheal resection, so as to reduce the incidence of airway dehiscence after the repair in large TEFs. 


\section{Abbreviation and Acronym}

$\mathrm{TEF}=$ tracheoesophageal fistula patches. Suck the bloody secretions away from the esophageal lumen to eliminate the possibility of aspiration through the fistula. The stomach conduit can be pulled up through the enlarged hiatus or with a laparotomy, depending on the patient's condition.

\section{DISCUSSION}

Acquired, benign TEF occurs as a rare complication of various disorders. Use of a covered self-expanding esophageal stent, a well-accepted palliative management in treating esophageal stricture and perforation, is becoming a more frequent cause of TEF in our practice. Large-sized pressure necrosis on the esophageal wall as well as the membranous portion of the trachea caused by the stent itself has become a cause for the development of large TEF.

Diagnosis of TEF can be made by computed tomographic scan, barium and/or water-soluble contrast esophagography, esophageal endoscopy, or bronchoscopy, and it may be useful in selected cases to inject methylene blue into the esophageal lumen during the course of bronchoscopy.

There have been case reports of TEFs repaired with plastic self-expanding esophageal stents ${ }^{2}$ and most recently endoscopic repair using fibrin glue and endoscopic suturing. ${ }^{3,4}$ However, for benign TEF, surgical correction is almost the only way to cure the TEF. Several techniques of repair have been described. ${ }^{5}$ Closing the defect of both the trachea and esophagus directly was used safely and with a high success rate in most cases. However, when the defect of the membranous tracheal wall is too large for single closure, a tracheal resection and/or reconstruction might be needed. The larger the TEF, the more likely a repair will be complicated by leakage at the repaired site owing to the tension at the anastomosis. This cannot always be avoided despite careful patient selection and meticulous surgical technique, especially if a resection has to be performed in the presence of the infection. The outcome and quality of life are often poor after these procedures, with high morbidity and mortality.

fused fistula within $2 \mathrm{~cm}$, to ensure the blood supply of the

TABLE 1. Clinical data of the patients

\begin{tabular}{|c|c|c|c|c|c|}
\hline Patient & Sex & Age & Diagnosis & Treatment & Follow-up \\
\hline 1 & Male & 11 & $\begin{array}{l}\text { TEF occurred } 8 \text { mo after stent placement for } \\
\text { esophageal caustic injury }\end{array}$ & $\begin{array}{l}\text { Tracheal fistula repair, partial esophagectomy } \\
\text { colon interposition }\end{array}$ & $9 \mathrm{y}$ \\
\hline 2 & Male & 38 & $\begin{array}{l}\text { TEF occurred } 2 \text { months after stent placement } \\
\text { for esophageal rupture caused by traffic } \\
\text { accident }\end{array}$ & Tracheal fistula repair, esophagogastrostomy & $3 \mathrm{y}$ \\
\hline 3 & Male & 22 & $\begin{array}{l}\text { TEF occurred } 5 \text { months after stent placement } \\
\text { for esophageal perforation caused by traffic } \\
\text { accident }\end{array}$ & Tracheal fistula repair, esophagogastrostomy & $14 \mathrm{mo}$ \\
\hline 4 & Male & 55 & $\begin{array}{r}\text { TEF occurred } 2 \text { years after stent placement for } \\
\text { esophageal rupture caused by chest trauma }\end{array}$ & Tracheal fistula repair, esophagogastrostomy & $15 \mathrm{mo}$ \\
\hline 5 & Female & 46 & $\begin{array}{l}\text { TEF occurred } 8 \text { months after stent placement } \\
\text { for esophageal rupture caused by chest } \\
\text { trauma }\end{array}$ & Tracheal fistula repair, esophagogastrostomy & $2 \mathrm{y}$ \\
\hline
\end{tabular}



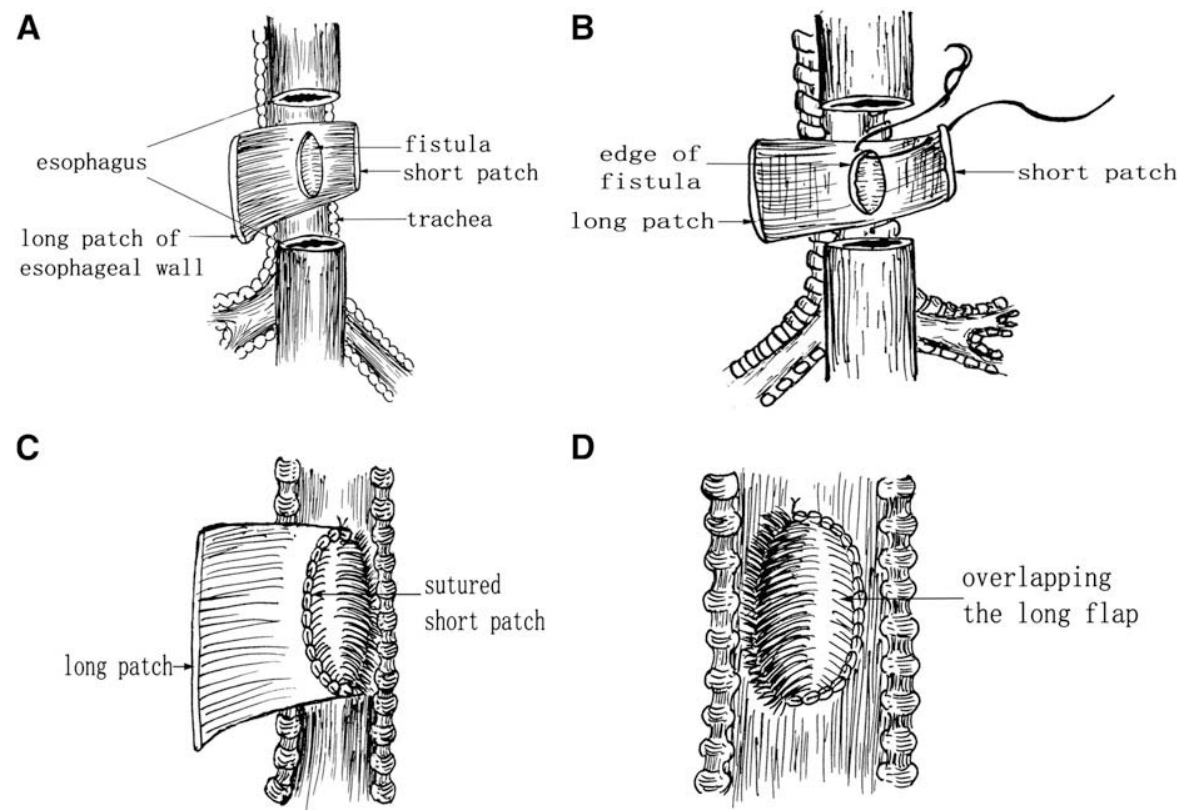

D

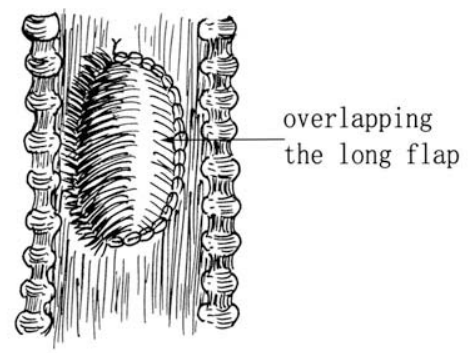

FIGURE 1. Double patch technique. A, The long and short patches with the fistula in between. B, The short patch was sutured full-thickness to the left edges. C, The fistula was closed with the short patch. D, The short patch was covered with the long esophageal wall patch.

In the presence of these difficulties, a patch to repair the defect on the trachea instead of resection may be fashioned. Autologous cartilage, muscle flaps, pericardium, or xenograft pericardium has been used to repair the defect. Some cases have even involved the use of a polytetrafluoroethylene patch (W.L. Gore \& Associates, Inc, Flagstaff, Ariz) ${ }^{6}$ or split-thickness skin graft. ${ }^{7}$ However, more convenient and viable materials for TEF repair are still sought, especially for large and complicated TEFs. As esophageal mucosa has been demonstrated to be a suitable viable material, ${ }^{8,9}$ it may be advisable to patch the wide tracheal defect with the wall of the esophagus, which has been described by Jougon and Couraud ${ }^{10}$ in treating a patient with a large TEF with good results after 4 years. In view of persistent infection, the large defect in the trachea, and friability of the tissues in our patients, we used a double patch TEF repair for patients. In this procedure, the esophageal wall was used to build a double-layered protective patch onto the tracheal defect through overlapping of both the long and short flaps. The continuity and blood supply of the esophageal flaps with the trachea were well preserved, which accordingly reduced the incidence of complications such as leakage and recurrence of TEF. Inasmuch as no tracheal resection and reconstruction were needed, the incidence of complications and the complexity of the operation were greatly reduced.

The appropriate lesions for this procedure are large TEFs for which tracheal resection could not be undertaken safely and easily for various reason. It is not advisable to apply this approach to patients with a small and simple TEF in whom the defect of both the trachea and esophagus can be closed directly.

In our cases, the defect on the esophagus was also massive and damaged to a certain degree by the scarred mucosa and inflammation; therefore, esophageal resection seemed unavoidable (Figure 2). The esophagus might be preserved by recruiting only part of its circumference for tracheal reconstruction in some selected small TEFs, but it might not be routinely used in large ones.

On the basis of our present results, we believe that esophageal reconstruction with stomach for managing massive stent-induced TEFs and large complicated or recurrent TEFs is worthwhile. Inasmuch as tracheal resection and reconstruction were not needed, the incidence of complications and the complexity of the operation would be greatly reduced. In the meanwhile, this operative step proved to be safe and reliable. It adds no morbidity but does add significant early and long-term clinical benefit. Direct closure of the esophageal defect can result in narrowing of the esophagus with consequent swallowing problems. By contrast, esophageal reconstruction with stomach results in much better quality of life for the patients in the long term.

How to harvest the stomach conduit depends on the condition of the patient. The conduit was mobilized completely by an experienced surgeon through the diaphragmatic hiatus in our patients. The procedure required only one abdominal incision and benefited the recovery of pulmonary function after the operation. However, for patients with a history of abdominal surgery, a large spleen, and for non-Asian 

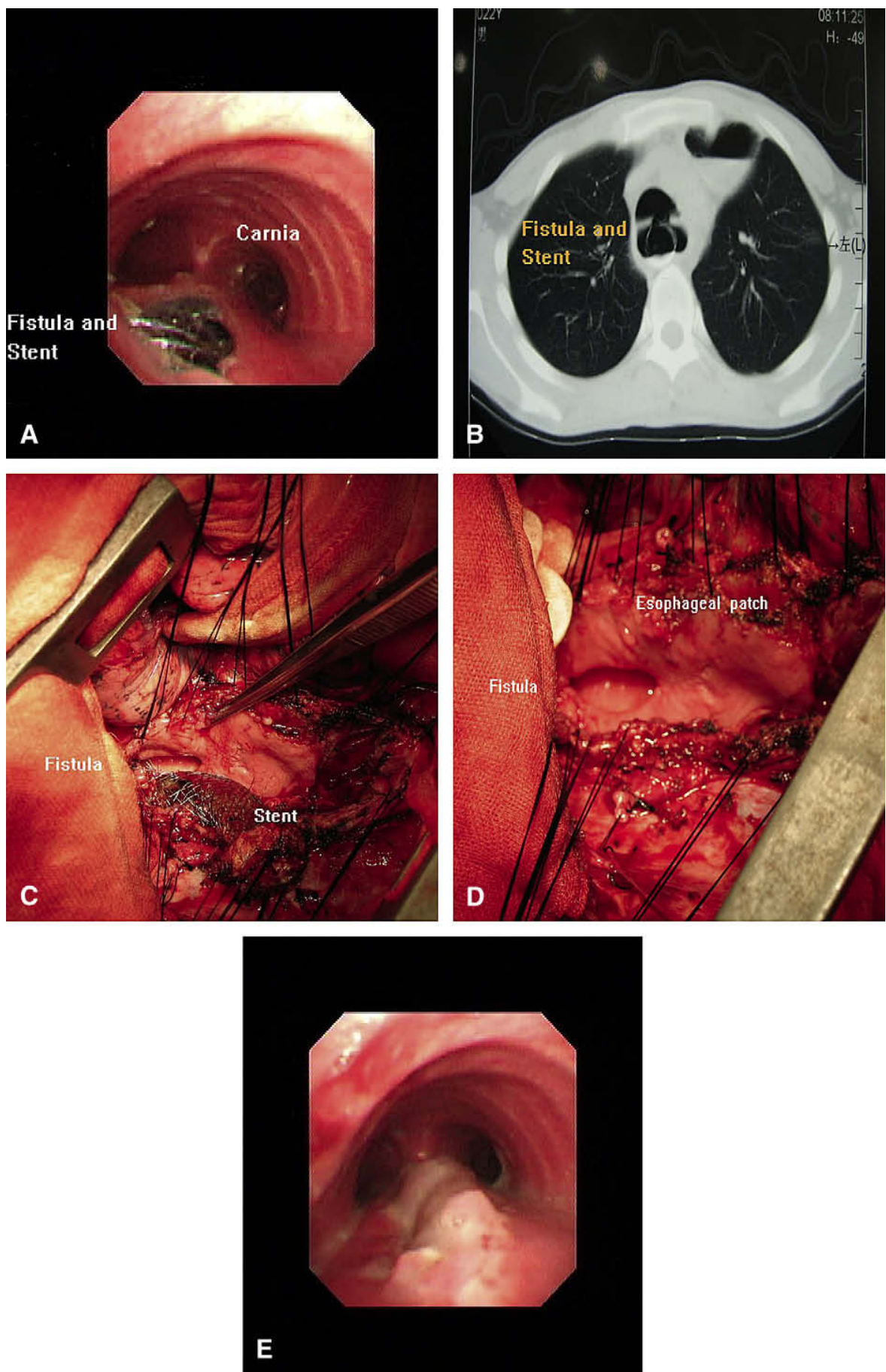

FIGURE 2. Bronchoscopic and intraoperative photographs of a 38-year-old male patient. TEF occurred 2 months after stent placement for esophageal rupture caused by a traffic accident. A, Bronchogram showed a large fistula in the membranous tracheal wall. B, Computed tomographic scan showed TEF with esophageal stent. C, The esophagus was opened, the fistula defect was found, and the stent was moved. D, Two esophageal patches were made and the fistula defect was exposed. E, Bronchogram 10 days after the operation showed that the defect was nicely repaired.

patients, because of body habitus constraints, it would be challenging and risky to mobilize the stomach in this way. Therefore, a laparotomy approach might be a better choice for these patients.
In summary, the salient feature of the procedure is that the portion of the esophageal wall with the fistula was made to form the double patch protective flap over the defect on the trachea. The fact that the incidence of complications is 
reasonably low indicates that it would be a reliable procedure in managing complicated and large TEFs.

We are grateful to Miss Fang Zhao for preparing the illustrations and Claude Deschamps, MD (Mayo Clinic), for his critical reading of the manuscript.

\section{References}

1. Flege JB Jr. Tracheoesophageal fistula caused by cuffed tracheostomy tube. Ann Surg. 1967;166:153-6.

2. Adler DG, Pleskow DK. Closure of a benign tracheoesophageal fistula by using a coated, self-expanding plastic stent in a patient with a history of esophageal atresia. Gastrointest Endosc. 2005;61:765-8.

3. Raju GS, Thompson C, Zwischenberger JB. Emerging endoscopic options in the management of esophageal leaks [videos]. Gastrointest Endosc. 2005;62:278-86.
4. Broto J, Asensio M, Verne JMT. Endoscopic treatment of tracheo-esophageal fistulas: fact or fiction? Circ Pediatr. 2003;16:69-72.

5. Macchiarini P, Verhoye JP, Chapelier A, Fadel E, Dartevelle P. Evaluation and outcome of different surgical techniques for postintubation tracheoesophageal fistulas. J Thorac Cardiovasc Surg. 2000;119:268-76.

6. Bardini R, Radicchi V, Parimbelli P, Tosato SM, Narne S. Repair of a recurrent benign tracheoesophageal fistula with a Gore-Tex membrane. Ann Thorac Surg. 2003;76:304-6.

7. Huang PM, Lee YC, Huang SC. Full thickness skin graft as a adjunct in the repair of a recurrent benign tracheoesophageal fistula. Thorac Cardivasc Surg. 2005;53: 65-7.

8. Utley JR, Dillon ML, Todd EP, Griffen WO, Zeok JV. Giant tracheosophageal fistula: management by esophageal diversion. J Thorac Cardiovasc Surg. 1978; 75:373-7.

9. Bartlett R. A procedure for management of acquired tracheoesophageal fistula in ventilator patients. J Thorac Cardiovasc Surg. 1976;71:89-95.

10. Jougon J, Couraud L. Esophageal patching for an unsuturable tracheoesophageal fistula. Eur J Cardiothoracic Surg. 1998;14:431-3. 